\title{
Examining the Learning Environment and Academic Performance in a Tertiary 3D Animation Course in
}

\author{
Macau \\ Kuan-Chen Tsai (Corresponding author) \\ Department of Art and Design, City University of Macau \\ T222, Tai Fung Building, Avenida Padre Tomás Pereira Taipa, Macau \\ Tel: 853-8590-2733Ｅ-mail: tsaikuanchen@cityu.mo
}

Received: March 10, 2017 Accepted: May 31, 2017 Published: September 1, 2017

doi:10.5296/ire.v5i2.11914 URL: http://dx.doi.org/10.5296/ire.v5i2.11914

\begin{abstract}
A significant effort has been made to study the impacts of the learning environment on students' academic performance. The main purpose of the current study was to investigate the possible link between the learning environment in a university and learning outcomes in students Chinese educational settings. The sample used in this study consisted of 128 students (recruiting from the third-year art and design program) from one private university in Macau. The results of the Pearson correlation showed us that the students' perception of their learning environment was not related to their academic performance. When we treated gender, residency status, and students' perception of their learning environment as independent variables to predict their academic performance, we again found that in the regression model, students' perception of their learning environment could not predict their academic performance. A number of limitations were also discussed; as a result, the interpretation of this study should be considered tentative.
\end{abstract}

Keywords: learning environment, academic performance, CUCEI, Macau

\section{Introduction}

Research has shown that the quality of the classroom environment has a significant influence on cognitive and affective learning outcomes (Dorman, 2014). As Dorman (2014) pointed out, "the fundamental question for learning environment researchers is: what is it really life looking like for students in this environment?” (p. 35). Indeed, the concept of environment in educational settings often refers to the atmosphere and tone that is purposely framed by educators. Consequently, it is believed that the link between the learning environment and 
learning outcomes should be significant.

\subsection{Research on the Learning Environment}

A significant effort has been made to study the impacts of the learning environment on students' academic performance (Kablan, 2016; Lyubovnikova, Napiersky, \& Vlachopoulos, 2015). With regard to the empirical data that is available in the literature on this subject, we should recognize that the "routine collection of evaluation data" does not guarantee any "improvement in teaching"; rather, "only serious collegial deliberation by teaching staff on the results of evaluations will bring about changes in teaching” (Dorman, 2014, p. 35).

Among university students, a number of empirical studies have found that the different factors of the learning environment produce different influences on academic performance and the learning experience. Malie and Akir (2012) found that hearing and explanation constitutes the learning environment preferred by most students. One study (Oluwatayo, Aderonmu, \& Aduwo, 2015) investigated Nigerian architecture students' perceptions of their learning environment, and the results suggested that different aspects of the learning environment can be manipulated by educators in order to improve the performance of their students. Mapuranga, Musingafi, and Zebron (2015) found that university students in Zimbabwe thought that university support services and funding were some of the most important determinants of their performance. In Taiwan, Hsu, Chiang, and Liang (2014) investigated the possible mediator effects of imagination on the learning environment and academic performance. Further, they compared the results of science and engineering major students. The findings suggest that in the science group, through the mediation of imagination, learning resources were the key factors in academic performance, whereas in the engineering group, the social climate had relatively strong effects on academic performance.

With the movement toward accountability in educational settings, a number of instruments can serve as the means to assess the well-being of university students. In North America, a popular instrument that was often used to assess effective teaching was the Students' Evaluations of Educational Quality (SEEQ; Marsh, 1982), which considered nine dimensions in teaching: learning/value, enthusiasm, organization, group interaction, individual rapport, and breadth of coverage, examinations /grading, assignments and workload/difficulty. In Australian universities, the Course Experience Questionnaire (CEQ; Ramsden, 1991) was regarded as a key performance indicator for universities. The CEQ examines five dimensions of course experience: clear goals and standards, generic skills, good teaching, appropriate workload, and appropriate assignment.

\subsection{Purpose of the Study}

There has been no Chinese research conducted in the field of art and design to date. Therefore, the main purpose of the current study was to investigate the possible link between the learning environment in a university and learning outcomes in students Chinese educational settings. More specifically, we wanted to discover the extent to which this link exists in those settings, and what role gender plays in this link. In addition, there are two major groups of students in tertiary education in Macau: domestic students with a permanent residency status 
(local) who speak Cantonese, and non-domestic students from mainland China (Mainland) who speak Mandarin. The two groups are ethnically similar, but have been raised in different social environments and educated differently. As a result, it is advantageous to differentiate between the two groups, and investigate whether being a Macau resident affects this relationship between the learning environment and academic performance.

\section{Method}

\subsection{Participants}

The sample used in this study consisted of 128 students from one private university in Macau. The students were recruited from the third-year art and design program in the university. Their average age was 21.84 years $(S D=2.77)$. There were 62 males and 66 females in the sample, with 92 students from Mainland China and 36 being local Macau students.

\subsection{Instruments}

The College and University Classroom Environment Inventory (CUCEI; Fraser \& Treagust, 1986) has been used previously as a tool to assess students' perception of their learning environment. CUCEI is an instrument used to evaluate the university class environment in seven dimensions: personalization, involvement, student cohesiveness, satisfaction, task orientation, innovation, and individualization. Personalization measures how many opportunities the student has to interact with the professor. Involvement assesses student participation in class. Student Cohesiveness assesses friendship with students. Satisfaction measures the level of enjoyment in class. Task Orientation measures the organization of class activities. Innovation assesses how often the instructor uses unusual class activities or teaching approaches. Finally, individualization measures how often the students are allowed to make decisions and to work at their own pace.

The CUCEI form has 49 items with a 4-point Likert response system that provides for a range of responses - from strongly disagree $=1$, to strongly agree $=4$. The scores were aggregated to form scale scores for each respondent. Dorman (2014) has provided evidence for the reliability and validity of using a CUCEI. In his study, the coefficient alpha for the seven dimensions ranged from .75 to .90, and the psychometric structure of the CUCEI was also confirmed by an exploratory factor analysis with varimax rotation indicating a seven-factor structure.

The academic performance of the students used in the current study was an aggregate score from their five projects in the animation course. In this course, the students were asked to use Autodesk MAYA to build 3D models and scenes. The five assigned projects were as follows: poster design, still life, product design, building design, and character design. The final score was aggregated from each of these five projects that is, each project accounted for $20 \%$ of the final score, and so, the maximum possible score was 100 .

\subsection{Procedure}

The participants were asked to complete the CUCEI online, because this course was held in the PC lab. The research team used Google Forms to create the survey, and provided its 
online link to students. Our participants were informed that participating in this survey was part of the course requirement, and that it would help the instructor to better understand their perception of the learning environment. The entire procedure took about 20 minutes to complete, and all concerns were addressed and questions were answered by the researcher who was participating in the session.

\section{Results}

The relationship between the seven elements in the CUCEI and academic performance was investigated using the Pearson product-moment correlation coefficient, as shown in Table 1. There were some positive correlations (e.g., in personalization) and negative correlations (e.g., in satisfaction). However, all the correlations were weak and not at significant levels ( $p$ $>$.05).

Table 1. Means, standard deviations, and intercorrelations for academic performance on the seven measures of CUCEI

\begin{tabular}{llllll}
\hline \multicolumn{1}{c}{ Measure } & $\mathrm{M}$ & & $\mathrm{SD}$ & $\mathrm{r}$ & $\mathrm{p}$ \\
\hline Personalization & 2.69 & .43 & -.107 & .846 & \\
Involvement & 2.82 & .38 & .011 & .898 & \\
Student cohesiveness & 2.61 & .53 & .045 & .611 & \\
Satisfaction & 2.65 & .42 & -.039 & .660 & .483 \\
Task orientation & 2.70 & .44 & -.063 & .186 & \\
Innovation & 2.57 & .43 & -.118 & .814 & \\
Individualization & 2.89 & .42 & -.021 & &
\end{tabular}

Regarding gender and residency status, an independent-samples t-test was conducted to compare the scores of CUCEI and academic performance for both groups. Table 2 shows that there was no significant difference in scores for males and females, except that the scores for satisfaction in males $(M=2.72, S D=.45)$ were higher than those of females $(M=2.58, S D$ $=.39), t(126)=2.01, p=.047$. In terms of residency status, students from Macau had higher academic performance scores $(M=79.06, S D=7.14)$ than those of Chinese students $(M=$ 75.05, $S D=7.29) ; t(126)=-2.81, p=.006$. In addition, students from Macau had higher scores for student cohesiveness $(M=2.82, S D=.66)$ than those of Chinese students $(M=$ 2.52, $S D=.45) ; t(126)=-2.48, p=.017$.

Table 2. Group Differences for Academic Performance and CUCEI

\begin{tabular}{lccccccc}
\hline \multicolumn{7}{c}{ Male } & \multicolumn{5}{c}{ Female } & & \\
\hline \multicolumn{1}{c}{ Measure } & M & SD & M & SD & t(126) & p \\
$\begin{array}{l}\text { Academic } \\
\text { performance }\end{array}$ & 76.44 & 7.55 & 75.94 & 7.39 & .38 & .708 \\
\hline
\end{tabular}




\section{I Macrothink}

\begin{tabular}{lcccccc}
\hline Personalization & 2.75 & .47 & 2.64 & .39 & 1.51 & .134 \\
Involvement & 2.83 & .43 & 2.81 & .33 & .33 & .745 \\
Student & 2.67 & .58 & 2.55 & .49 & 1.24 & .219 \\
cohesiveness & & & & & & \\
Satisfaction & 2.72 & .45 & 2.58 & .39 & 2.01 & .047 \\
Task orientation & 2.74 & .47 & 2.65 & .40 & 1.71 & .244 \\
Innovation & 2.63 & .44 & 2.52 & .41 & 1.45 & .149 \\
Individualization & 2.91 & .44 & 2.87 & .40 & .48 & .63 \\
& & China & & Macau & & \\
Academic & 75.05 & 7.29 & 79.06 & 7.14 & -2.81 & .006 \\
performance & & & & & & \\
Personalization & 2.64 & .40 & 2.83 & .48 & -2.31 & .022 \\
Involvement & 2.85 & .40 & 2.75 & .33 & 1.31 & .193 \\
Student & 2.52 & .45 & 2.82 & .66 & -2.48 & .017 \\
cohesiveness & & & & & & \\
Satisfaction & 2.61 & .36 & 2.74 & .54 & -1.29 & .205 \\
Task orientation & 2.66 & .42 & 2.79 & .46 & -1.60 & .112 \\
Innovation & 2.55 & .42 & 2.63 & .45 & -.86 & .391 \\
Individualization & 2.92 & .44 & 2.82 & .37 & 1.22 & .226 \\
\hline
\end{tabular}

In order to understand the possible effects of gender, residency status, and students' perception of the learning environment, on their academic performance, we conducted a stepwise regression analysis to examine which variables were able to predict a significant amount of the variance. According to the model, $F(126)=7.89, p=.006, R^{2}=.059$, explaining $5.9 \%$ of the variance in academic performance. As Table 3 shows, only residency status (students from Macau or China) was a valid predictor of the students' academic performance, with $\beta=.24$.

Table 3. Stepwise regression analysis summary for nine variables predicting academic performance

\begin{tabular}{|c|c|c|c|c|c|}
\hline Variable & B & SE B & $\beta$ & $\mathrm{t}$ & $\mathrm{p}$ \\
\hline Status & 4.00 & 1.43 & .24 & 2.81 & .006 \\
\hline \multicolumn{6}{|l|}{ Excluded variables } \\
\hline Gender & & & -.03 & -.33 & .741 \\
\hline Personalization & & & -.07 & -.78 & .435 \\
\hline Involvement & & & .04 & .46 & .647 \\
\hline $\begin{array}{c}\text { Student } \\
\text { cohesiveness }\end{array}$ & & & -.02 & -.19 & .853 \\
\hline Satisfaction & & & -.07 & -.84 & .402 \\
\hline Task orientation & & & -.10 & -1.13 & .259 \\
\hline Innovation & & & -.14 & -1.59 & .114 \\
\hline Individualization & & & .01 & .06 & .952 \\
\hline
\end{tabular}




\section{Discussion}

The results of the Pearson correlation showed us that the students' perception of their learning environment was not related to their academic performance. This finding was unexpected. A possible reason for this observation is that we used the final score from the Animation course, in which the academic performance was an aggregated score from five projects (each accounting for $20 \%$ of the final score). In other studies, scores from a traditional paper-and-pencil test have usually been treated as indicators of academic performance. However, in our study, we tested students' creative production, and this might have contributed to these unexpected results. As a result, it would be prudent to conduct further studies of the art and design field based on similar lines to clarify this issue. To our knowledge, it is the first study to use CUCEI in art and design course. It is believed that this research direction is promising; as a result, more art and design educator could pursue this line of research in other courses in order to clarify the results.

When we treated gender, residency status, and students' perception of their learning environment as independent variables to predict their academic performance, we again found that in the regression model, students' perception of their learning environment could not predict their academic performance. Only residency status (that is, whether the students is from Macau or from mainland China) can predict a student's academic performance; however, this variable can only explain $5.9 \%$ of the variance in the academic performance.

The interpretation of this study should be considered tentative, and for an enhanced understanding of the association between the learning environment and learning outcomes, further studies involving a wider sample of students in other institutions, and in other countries, should be conducted. Furthermore, part of the data was based on participants' self-reports, and could thus be affected by possible biases (for example, by the desire to provide socially acceptable responses). The academic performance score was aggregated from five projects in the animation course; therefore, the generalizability of the results is not guaranteed. Although such limitations exist in the current study, this exploratory study does provide useful information and findings for art educators and researchers.

\section{Conclusion}

In our study, we examined the possible relationship between academic performance and the learning environment in students from Macau and mainland China in a third-year art and design course. No correlation between the two variables was found. In addition, neither residency status nor gender significantly affected this relationship between the learning environment and academic performance. Nevertheless, owing to the unexpected results from using the scores for projects involving creative production as the scores for academic performance in our survey, it is hereby suggested that more research in other art and design courses be conducted in order to validate our observations. 


\section{References}

Dorman, J. P. (2014). Classroom psychosocial environment and course experiences in pre-service teacher education courses at an Australian university. Studies in Higher Education, 39, 34-47.

Fraser, B. J., \& Treagust, D. F. (1986). Validity and use of an instrument for assessing classroom psychological environment in higher education. Higher Education, 15, 37-57.

Hsu, M.-C., Chiang, C., \& Liang, C. (2014). The mediator effects of imagination between learning environment and academic performance: A comparison between science and engineering majors. International Journal of Technology and Design Education, 24(4), 419-436.

Kablan, Z. (2016). The effect of manipulatives on mathematics achievement across different learning styles. Educational Psychology, 36(2), 277-296.

Lyubovnikova, J., Napiersky, U., Vlachopoulos, P. (2015). How are task reflexivity and intercultural sensitivity related to the academic performance of MBA students? Studies in Higher Education, 40(9), 1694-1714.

Malie, S., \& Akir, O. (2012). Bridging the gaps between learning and teaching through recognition of students' learning approaches: A case study. Research in Education, 87, 75-94.

Mapuranga, B., Musingafi, M. C. C., \& Zebron, S. (2015). Students perceptions of factors that affect their academic performance: The case of Great Zimbabwe University (GZU). Journal of Education and Practice, 6(18), 1-5.

Marsh, H. W. (1982). SEEQ: A reliable, valid and useful instrument for collecting students' evaluations of university teaching. British Journal of Educational Psychology, 52, 77-95.

Oluwatayo, A. A., Aderonmu, P. A., \& Aduwo, E. B. (2015). Architecture students' perceptions of their learning environment and their academic performance. Learning Environments Research, 18, 129-142.

Ramsden, P. (1991). A performance indicator of teaching quality in higher education: The Course Experience Questionnaire. Studies in Higher Education, 16, 129-150.

\section{Copyright Disclaimer}

Copyright reserved by the authors.

This article is an open-access article distributed under the terms and conditions of the Creative Commons Attribution license (http://creativecommons.org/licenses/by/3.0/). 